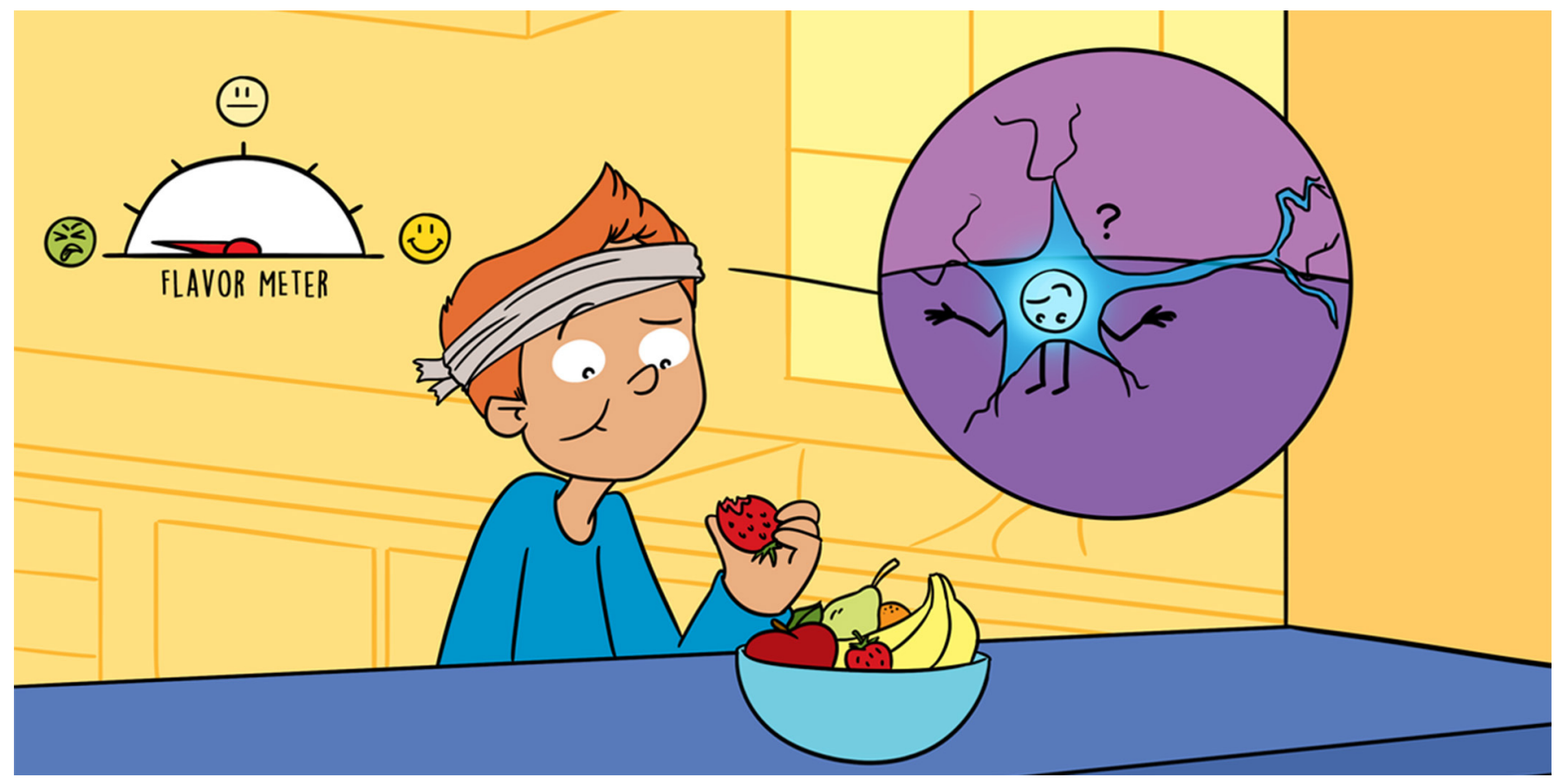

\title{
WHAT DO WE LEARN FROM STUDYING TRAUMATIC BRAIN INJURY?
}

\section{Kristin Wilmoth and Michael McCrea *}

Department of Neurosurgery, Medical College of Wisconsin, Milwaukee, WI, United States

\section{YOUNG REVIEWERS:}

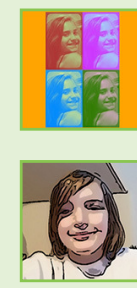

ELLA

AGE: 9

TOMOS

AGE: 12
A hard bump to the head can cause traumatic brain injury (TBI). Doctors treat more than 2 million Americans with TBI every year. Common causes of TBI are car crashes or hitting your head. Some TBIs are severe and some are milder. All TBIs can have serious effects, which include bleeding, brain swelling, or tearing of the brain's connections. It is important for researchers to study TBI, so that they can find ways to help those with a brain injury to get better. With this common goal in mind, scientists around the world are researching TBI. People with TBI often come to hospitals or clinics and some become part of research studies. TBI researchers follow athletes and military service members, too, because their activities increase the risk of TBI. In this paper, we review different types of TBI studies. We also discuss the groups helping scientists. We will also tell you how you could become a future TBI researcher! 


\section{Figure 1}

A bump to the head while playing sports can cause a concussion

TRAUMATIC BRAIN INJURY (TBI)

A hit or jolt to the head that makes it difficult for the brain to work properly.

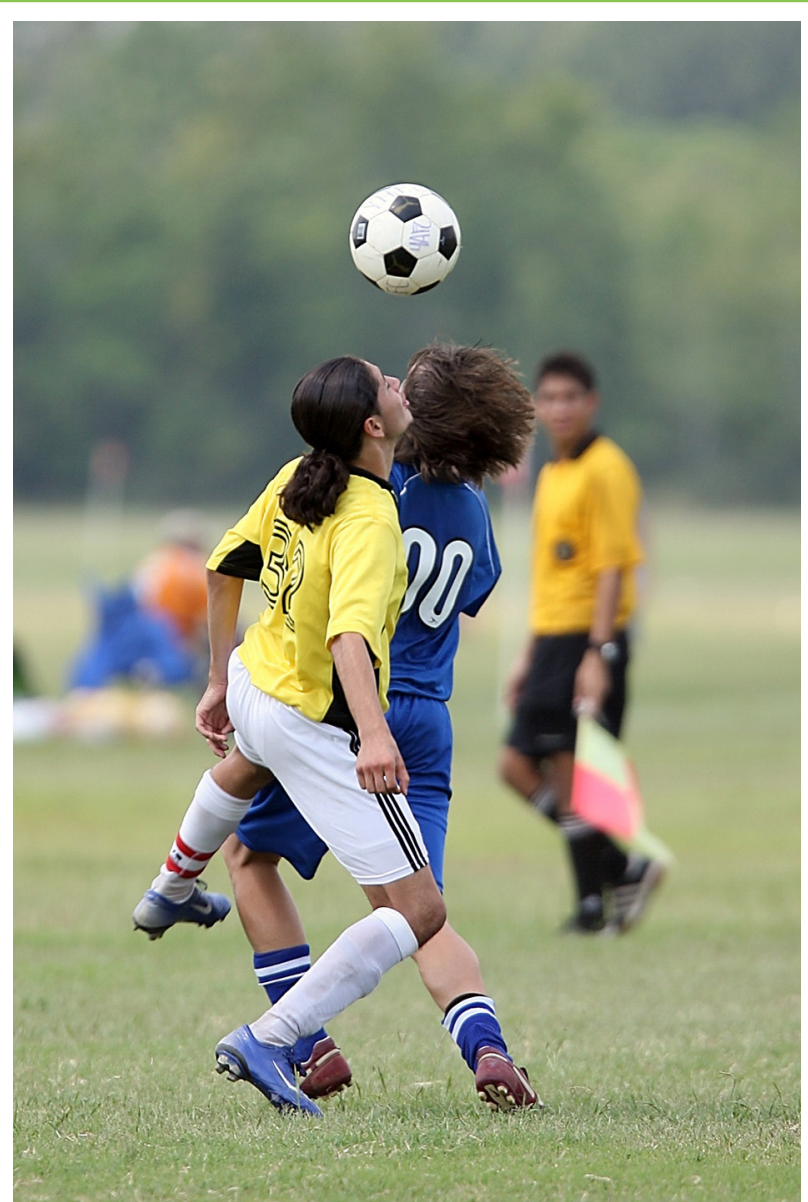

Figure 1

\section{TBI-WHAT IS THE BIG DEAL?}

A traumatic brain injury (TBI) is caused by a hit to the head. This trauma makes it difficult for the brain to operate normally. Every hour, over 7,000 people worldwide experience a TBI [1]. It would take more than 100 school buses to carry them all! Some people are at higher risk for TBI. For example, TBI is more likely for babies and grandparents than parents. There are many causes of TBI. TBI can result from falling and hitting your head, or by something hitting your head with force. Jolting your head suddenly can cause a TBI as well. Car and other vehicle crashes are a common way people get TBIs, and you could also get a TBI from a crash on your bike or skateboard. Another common cause is playing sports, like soccer or football (Figure 1). Your head could collide with another player or with the ground while you are playing. Bomb blasts on the battlefield are a main cause of TBI for people in the armed forces.

\section{WHAT HAPPENS TO THE BRAIN IN A TBI?}

TBI can damage the brain in several ways, which is why one TBI can be very different from another. The injury could tear the skin or crack 
Figure 2

Some TBIs result in a buildup of blood inside the skull, which can be very dangerous

(Scientific Animations Inc.

https://commons.wikime dia.org/wiki/File:Types_ of_Intracranial_ hematoma.jpg,

Cropped by the authors to show subdural hematoma,

https://creativecommons org/licenses/by-sa/4.0/ legalcode).

\section{NEUROSURGEON}

A doctor who is trained to perform surgery on the brain or spine.

\section{CONCUSSION}

A mild traumatic brain injury, in which recovery happens within the first few weeks to months.

\section{NEURONS}

Brain cells that carry specialized messages.

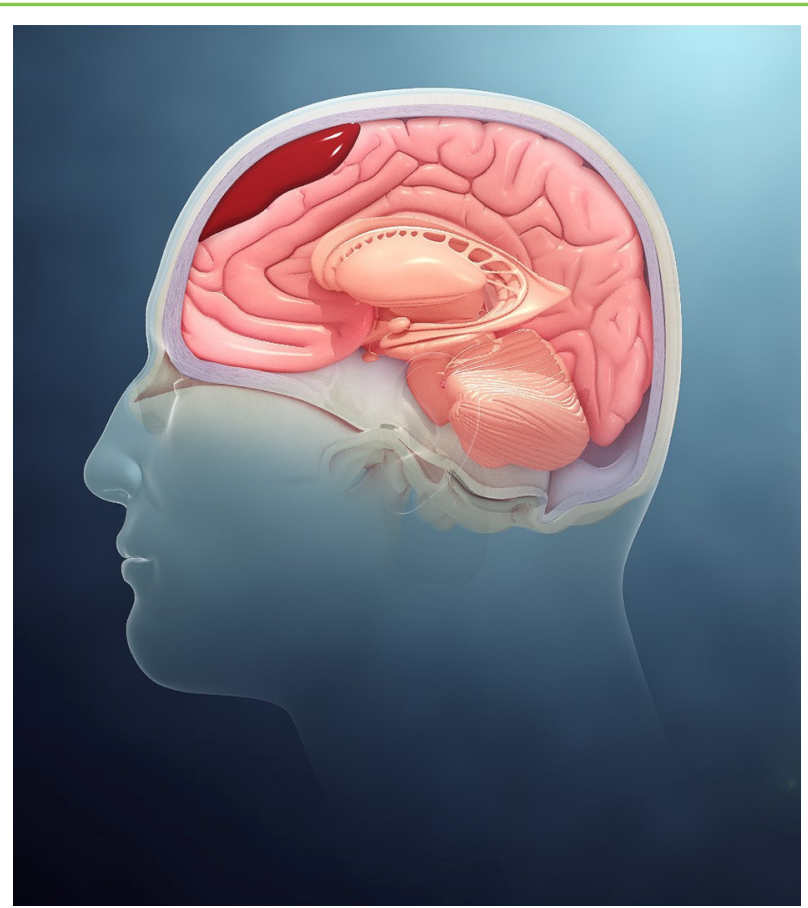

Figure 2

the skull at the site of impact. The damage to the brain might stay in one place or be spread across the brain. If blood or liquid builds up inside the skull, this can be very dangerous. Figure 2 shows a drawing of a head and brain and Figure 3 shows a brain scan of blood inside the skull after TBI. In Figures 2, 3, the red shows blood sitting inside the skull. This can be life threatening. A neurosurgeon, a doctor who performs surgery on the brain or spine, can stop the bleeding and fix the pressure building up in the brain.

Concussion means the same thing as mild TBI. The brain does not usually bleed after a concussion. The brain is made up of more than 60 billion neurons, which are very long nerve cells that send messages around the body using tiny chemicals [2]. A concussion can tear neurons or make it harder for neurons to work properly. The worse the injury, the longer it takes for the brain to return to normal. A TBI can damage the neurons that are responsible for senses like taste and smell. For example, a person might have a poor sense of smell after TBI.

\section{HOW ARE PEOPLE AFFECTED BY TBI?}

People can become unconscious, or "knocked out," for some time after a TBI. They might seem confused or have problems talking when they wake up. They will often not remember what happened to them. Recovery from a mild TBI can take a couple of days to a few weeks, and for some people with more serious TBI, it takes longer. Symptoms of TBI include difficulty thinking, remembering, or paying attention. 
Figure 3

Brain scans can detect bleeding inside the skull after TBI.

\section{CLINICAL}

\section{RESEARCH}

The study of people or human tissue to better understand health and disease.

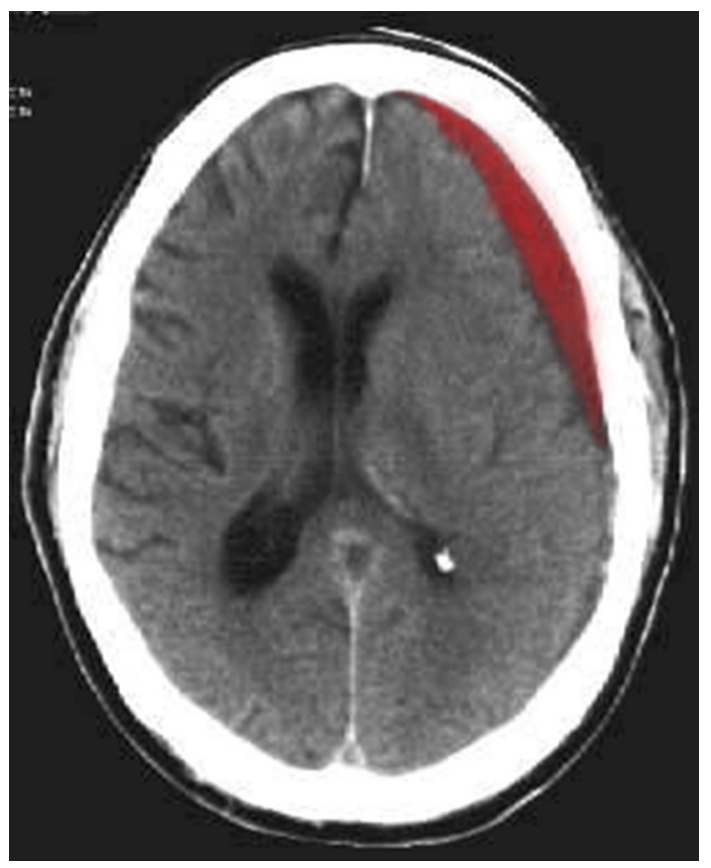

Figure 3

Changes in the body, like headaches, feeling dizzy, or throwing up, are also common symptoms of TBI. Some people experience changes to their moods. They might feel more nervous or upset. To recover from a TBI, the injured person might need to stay home from work or school and take a break from sports, to let the brain rest. A doctor will be able to tell the TBI patient when it is safe to go back to these activities.

More severe TBIs have the potential for serious problems. These problems are often related to swelling and bleeding inside the skull. Emergency treatment for symptoms might be needed, such as help with breathing using a machine. Recovery from a moderate or severe $\mathrm{TBI}$ can take months to years. The symptoms of severe TBI can be very different from one person to the next, depending on the severity of the injury and the areas of the brain that are injured. In some cases, one side of the body may be in a paralyzed-like state, and the person may have a hard time moving his affected arm or leg. Therapists can help to re-train a patient's brain to control his or her limbs. Another common problem following TBI is difficulty with talking. Speech therapy helps patients with $\mathrm{TBI}$ communicate better.

\section{WHY IS IT IMPORTANT TO STUDY TBI?}

Clinical research is the study of people and how we function. This research aims to provide a better understanding of health and disease. Brain injury research is often about helping people with TBI. We want to understand exactly what happens to the brain after TBI so that we can develop better life-saving measures and prevent some of the serious 
consequences of TBI. Another important research focus is accurately diagnosing TBI, because a quick and accurate diagnosis allows doctors to act fast to help the injured person. Another goal of TBI research is understanding which kinds of treatments are best, and which things might help or harm a person during recovery. To study $\mathrm{TBI}$, doctors often use brain scans, which can identify bleeding or other problems after injury. TBI researchers are always searching for new solutions, such as medicines and therapies, to help people make a good recovery after TBI.

\section{WHAT IS TEAM-BASED RESEARCH ON TBI?}

To study TBI, scientists work in teams made of different kinds of doctors. Each doctor can offer unique thoughts about how to set up the study. Scientists generally study three main groups of people with TBI. The first group is the general population, made of everyday people, like me and you, who might get injured. The second group is athletes who often get concussion from playing sports. The third group is military service members, because people in the armed forces are more likely to have a TBI when in combat.

The International Initiative for Traumatic Brain Injury Research (InTBIR) studies TBI on a global scale. This group includes countries in Europe, the U.S., and Canada. An example of an InTBIR study is called Transforming Research and Clinical Knowledge in TBI (TRACK-TBI). TRACK-TBI researchers see patients in clinics and emergency rooms right after their injuries. The researchers measure different forms of $\mathrm{TBI}$, from mild concussion to coma. They follow up with the patients in the weeks to months after their injuries. The researchers want to see how things turn out for the patients after TBI. TRACK-TBI has made important discoveries about what happens to the brain after TBI, and they also have findings on the best ways to treat different forms of TBI $[3,4]$.

The National Collegiate Athletic Association and the Department of Defense have a study called the Concussion Assessment, Research and Education (CARE) Consortium [5]. CARE studies student athletes that attend U.S. colleges and military service academies. Before they start playing their sports, the athletes get tested for abilities that get worse after a concussion. Their abilities before they start playing sports are called the baseline. When athletes get concussions, they stop playing sports and their brain health is tested again several times, until they seem better. Then, CARE studies these tests to learn about the way the brain recovers from TBI. CARE answers important questions about how concussion affects the brain [5].

TRACK-TBI and CARE collect a variety of information about people and their TBIs, including details about the injuries and treatments. Researchers collect these data using brain scans, blood samples, brain 
function tests, and surveys. Helmet sensors can be used to measure how hard of a hit the athlete took. Did you know a concussion affects the movements of your eyes? Some sensors can measure eye movements, so researchers can track this information, too. Researchers are also exploring whether a person's genes play a role in recovery from $\mathrm{TBI}$.

\section{HOW MIGHT A PERSON BECOME A TBI SCIENTIST?}

Do you want to become a future TBI researcher? Education is the most important step! To start, high school and college degrees are important. Most TBI researchers need lots of schooling to help build specialized skills. A medical degree or graduate degree is the most common. Other researchers choose a certificate program, such as one in clinical research. In these programs, students will often study research, the brain, or human behavior. Teachers and mentors train future scientists by working together with their students to prepare them for independent research. Formal programs are available to students interested in research [6]. Look for things like summer internships, which allow high school or college students to study science and practice research. You can learn about TBI on your own, too! Ask a librarian to help you search for scientific books or papers on TBI. Then read about the current TBI research that is being done. This will help you to better understand what studies you could explore next! Find something you are interested in. Then, reach out to the people doing that work. Tell them how interested you are and ask them if you can come visit or be involved with their research team. You never know where it might lead!

\section{REFERENCES}

1. Dewan, M. C., Rattani, A., Gupta, S., Baticulon, R. E., Hung, Y. C., Punchak, M., et al. 2019. Estimating the global incidence of traumatic brain injury. J. Neurosurg. 130:1080-97. doi: 10.3171/2017.10.JNS17352

2. von Bartheld, C. S., Bahney, J., and Herculano-Houzel, S. 2016. The search for true numbers of neurons and glial cells in the human brain: a review of 150 years of cell counting. J. Comp. Neurol. 524:3865-95. doi: 10.1002/cne.24040

3. Bodien, Y. G., McCrea, M., Dikmen, S., Temkin, N., Boase, K., Machamer, J., et al. 2018. Optimizing outcome assessment in multicenter TBI trials: perspectives from TRACK-TBI and the TBI endpoints development initiative. J. Head Trauma Rehabil. 33:147-57. doi: 10.1097/HTR.0000000000000367

4. Seabury, S. A., Gaudette, E., Goldman, D. P., Markowitz, A. J., Brooks, J., McCrea, M. A., et al. 2018. Assessment of follow-up care after emergency department presentation for mild traumatic brain injury and concussion: results from the TRACK-TBI study. JAMA Netw. Open 1:e180210. doi: 10.1001/jamanetworkopen.2018.0210

5. Broglio, S. P., McCrea, M., McAllister, T., Harezlak, J., Katz, B., Hack, D., et al. 2017. A National Study on the effects of concussion in collegiate athletes and US 
Military Service Academy members: the NCAA-DoD Concussion Assessment, Research and Education (CARE) consortium structure and methods. Sports Med. 47:1437-51. doi: 10.1007/s40279-017-0707-1

6. Nemeroff, L. 2016. Summer Programs for Students. American Psychological Association. Available online at: https://www.apa.org/ed/precollege/psn/ 2016/01/summer-programs

SUBMITTED: 13 May 2019; ACCEPTED: 16 December 2019; PUBLISHED ONLINE: 17 January 2020.

EDITED BY: Amy J. Markowitz, University of California, San Francisco, United States

CITATION: Wilmoth K and McCrea M (2020) What Do We Learn From Studying Traumatic Brain Injury? Front. Young Minds 7:158. doi: 10.3389/frym.2019.00158

CONFLICT OF INTEREST: The authors declare that the research was conducted in the absence of any commercial or financial relationships that could be construed as a potential conflict of interest.

COPYRIGHT @ 2020 Wilmoth and McCrea. This is an open-access article distributed under the terms of the Creative Commons Attribution License (CC BY). The use, distribution or reproduction in other forums is permitted, provided the original author(s) and the copyright owner(s) are credited and that the original publication in this journal is cited, in accordance with accepted academic practice. No use, distribution or reproduction is permitted which does not comply with these terms.

\section{YOUNG REVIEWERS}

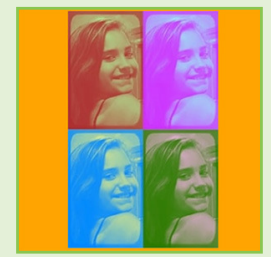

\section{ELLA, AGE: 9}

$\mathrm{Hi}$, my name is Ella. I just started fourth grade and I really like it. I do gymnastics and am on the competitive team for Ninja Warriers.

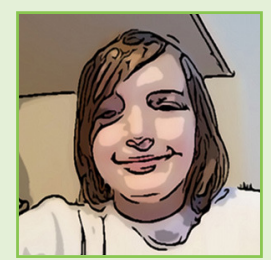

\section{TOMOS, AGE: 12}

I am 12 years old and at high school in Scotland. I really enjoy STEM subjects but also history and politics. My hobbies are cricket, football stats, and watching TV.

\section{AUTHORS}

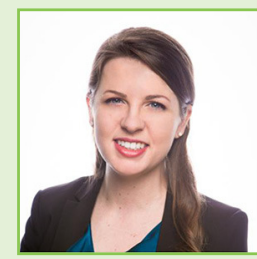

\section{KRISTIN WILMOTH}

I am a post-doctoral fellow in neuropsychology at the Medical College of Wisconsin. I earned my Ph.D. from the University of Texas Southwestern Medical Center in Dallas, where I also completed my internship training. I completed my dissertation on sport-related concussion in youth athletes. In addition to my clinical and research duties, I have enjoyed being involved in several professional organizations for 
neuropsychology and brain injury. I love my work, but I also like to sing, volunteer, and travel to new places!

\section{MICHAEL MCCREA}

I am a professor in the Department of Neurosurgery at the Medical College of Wisconsin. I am an active researcher in the study of traumatic brain injury. I earned my Ph.D. from the University of Wisconsin-Milwaukee. Then I completed my internship training in neuropsychology at Vanderbilt University School of Medicine, followed by a post-doctoral fellowship in clinical neuropsychology at Northwestern University Medical School. I have served on several international expert panels related to research and clinical care for TBI. *mmccrea@mcw.edu 